\title{
Papillary Thyroid Carcinoma with Exclusive Involvement of a Functioning Recurrent Laryngeal Nerve may be Treated with Shaving Technique
}

\author{
Naval Bansal · S. K. Mishra • M. Sabaretnam
}

Published online: 5 February 2015

(C) Société Internationale de Chirurgie 2015

\section{Dear Editor}

We have read article by Hyoung Shin Lee, ET al [1] and we appreciate authors' fine contribution on locally invasive thyroid cancer involving recurrent laryngeal nerve (RLN) that in selective subset of patients, tumor can be shaved off from the nerve with minimal adverse outcome. However, there are certain observations in the article that need further comments.

Was the nerve invaded by the primary thyroid tumor or by lymph nodes? Did the presence of central compartment lymph nodes had an impact on loco-regional recurrence [2]? Also whether recurrent cases were those who had positive central compartment lymphadenopathy?

Whether histological variant of papillary thyroid carcinoma (PTC) was taken into consideration during outcome analyses as biological behavior of PTC is different among its variants [3]? Preserving quality voice was the aim of this study while minimizing the adverse outcome, so, why authors did not considered doing nerve anastamosis in Group A patients.
In developing country like ours, we also encounter large tumors with aggressive variants; however, the finding of isolated nerve involvement is quite rare. We also agree with author's perspective that nerve preservation should be considered in cases of differentiated thyroid cancer where facilities for adjuvant radio-iodine ablation are available.

\section{References}

1. Lee HS, Kim SW, Park T, Nam GY, Hong JC, Lee KD (2014) Papillary thyroid carcinoma with exclusive involvement of a functioning recurrent laryngeal nerve may be treated with shaving technique. World J Surg. doi:10.1007/s00268-014-2906-3

2. Joo JY, Jin J, Seo ST, Lim YC, Rha KS, Koo BS (2014) Recurrence in regional lymph nodes after total thyroidectomy and neck dissection in patients with papillary thyroid cancer. Oral Oncol 51(2):164-169

3. Chrisoulidou A, Boudina M, Tzemailas A, Doumala E, Iliadou PK, Patakiouta F et al (2011) Histological subtype is the most important determinant of survival in metastatic papillary thyroid cancer. Thyroid Res 4(1):12
N. Bansal · S. K. Mishra $\cdot$ M. Sabaretnam $(\bowtie)$

Endocrine Surgery Department, Sanjay Gandhi Postgraduate

Institute of Medical Sciences, Lucknow, India

e-mail: drretnam@gmail.com 